\title{
Incidental irradiation of internal mammary lymph nodes in breast cancer: conventional two-dimensional radiotherapy versus conformal three-dimensional radiotherapy*
}

\author{
Irradiação incidental da cadeia mamária interna no câncer de mama: comparação entre a técnica \\ convencional (bidimensional) e a técnica tridimensional
}

\section{Elton Trigo Teixeira Leite ${ }^{1}$, Rafael Tsuneki Ugino ${ }^{2}$, Marco Antônio Santana ${ }^{3}$, Denis Vasconcelos Ferreira ${ }^{3}$, Maurício Russo Lopes ${ }^{2}$, Edilson Lopes Pelosi ${ }^{2}$, João Luis Fernandes da Silva², Heloisa de Andrade Carvalho ${ }^{4}$}

Leite ETT, Ugino RT, Santana MA, Ferreira DV, Lopes MR, Pelosi EL, Silva JLF, Carvalho HA. Incidental irradiation of internal mammary lymph nodes in breast cancer: conventional two-dimensional radiotherapy versus conformal three-dimensional radiotherapy. Radiol Bras. 2016 Mai/Jun;49(3):170-175.

Abstract Objective: To evaluate incidental irradiation of the internal mammary lymph nodes (IMLNs) through opposed tangential fields with conventional two-dimensional (2D) or three-dimensional (3D) radiotherapy techniques and to compare the results between the two techniques.

Materials and Methods: This was a retrospective study of 80 breast cancer patients in whom radiotherapy of the IMLNs was not indicated: 40 underwent 2D radiotherapy with computed tomography for dosimetric control, and 40 underwent 3D radiotherapy. The total prescribed dose was 50.0 Gy or 50.4 Gy (2.0 or 1.8 Gy/day, respectively). We reviewed all plans and defined the IMLNs following the Radiation Therapy Oncology Group recommendations. For the IMLNs, we analyzed the proportion of the volume that received 45 Gy, the proportion of the volume that received 25 Gy, the dose to $95 \%$ of the volume, the dose to $50 \%$ of the volume, the mean dose, the minimum dose (Dmin), and the maximum dose (Dmax).

Results: Left-sided treatments predominated in the 3D cohort. There were no differences between the 2D and 3D cohorts regarding tumor stage, type of surgery (mastectomy, breast-conserving surgery, or mastectomy with immediate reconstruction), or mean delineated IMLN volume (6.8 vs. $5.9 \mathrm{~mL} ; p=0.411$ ). Except for the Dmin, all dosimetric parameters presented higher mean values in the 3D cohort $(p<0.05)$. The median Dmax in the 3D cohort was 50.34 Gy. However, the mean dose to the IMLNs was 7.93 Gy in the 2D cohort, compared with 20.64 Gy in the 3D cohort.

Conclusion: Neither technique delivered enough doses to the IMLNs to achieve subclinical disease control. However, all of the dosimetric parameters were significantly higher for the 3D technique.

Keywords: Lymph nodes/radiation effects; Lymphatic irradiation; Breast neoplasms; Radiotherapy.

Resu mo Objetivo: Avaliar a irradiação incidental dos linfonodos da cadeia mamária interna (LCMls) com campos tangenciais opostos por meio de radioterapia bidimensional (2D) convencional ou tridimensional (3D) e comparar as duas técnicas quanto aos resultados obtidos. Materiais e Métodos: Trata-se de um estudo retrospectivo com 80 pacientes com câncer de mama sem indicação de radioterapia dos LCMIs: 40 foram submetidos a radioterapia 2D com tomografia computadorizada para controle dosimétrico e 40 foram submetidos a radioterapia 3D. A dose total prescrita foi 50,0 Gy ou 50,4 Gy (2,0 ou 1,8 Gy/dia, respectivamente). Os planos de tratamento foram analisados e os LCMIs foram definidos conforme as recomendações do Radiation Therapy Oncology Group. No tocante aos LCMIs, foram analisadas a proporção do volume que recebeu 45 Gy, a proporção do volume que recebeu 25 Gy, a dose para 95\% do volume, a dose para $50 \%$ do volume, a dose média, a dose mínima (Dmín) e a dose máxima (Dmáx).

Resultados: Tratamentos do lado esquerdo predominaram na coorte 3D. Não houve diferenças entre as coortes 2D e 3D quanto ao estágio do tumor, ao tipo de cirurgia (mastectomia, cirurgia conservadora ou mastectomia com reconstrução imediata) ou à média do volume delineado dos LCMIs (6,8 vs. 5,9 mL; $p=0,411)$. À exceção da Dmín, todos os parâmetros dosimétricos apresentaram médias maiores na coorte 3D ( $p<0,05)$. A mediana da Dmáx na coorte 3D foi 50,34 Gy. No entanto, a dose média nos LCMls foi 7,93 Gy na coorte 2D e 20,64 Gy na coorte 3D.

Conclusão: Nenhuma das duas técnicas emitiu doses suficientes aos LCMls para que se alcançasse o controle subclínico da doença. No entanto, todos os parâmetros dosimétricos foram significativamente maiores com a técnica 3D.

Unitermos: Linfonodos/efeitos de radiação; Irradiação linfática; Neoplasias da mama; Radioterapia.

* Study conducted in the Radiation Oncology Department, Hospital Sírio-Libanês, São Paulo, SP, Brazil.

1. MD, Radiation Oncologist, Radiation Oncology Department - Hospital SírioLibanês; Radiation Oncology Department - Instituto do Câncer do Estado de São Paulo Octavio Frias de Oliveira (Icesp), São Paulo, SP, Brazil.

2. MD, Radiation Oncologist, Radiation Oncology Department - Hospital SírioLibanês, São Paulo, SP, Brazil.
3. MD, Radiation Oncologist, Department of Radiology and Oncology - Faculdade de Medicina da Universidade de São Paulo (FMUSP), São Paulo, SP, Brazil.

4. MD, PhD, Department of Radiology and Oncology - Faculdade de Medicina da Universidade de São Paulo (FMUSP), São Paulo, SP, Brazil.

Mailing address: Dr. Elton Trigo Teixeira Leite. Hospital Sírio-Libanês. Rua Dona Adma Jafet, 91, Bela Vista. São Paulo, SP, Brazil, 01308-050. E-mail: eltontt@gmail.com. Received January 7, 2015. Accepted after revision June 1, 2015. 


\section{INTRODUCTION}

For more than two decades, the standard of care for patients with early stage breast cancer has been breast-conserving therapy. Radiation therapy (RT), with or without a boost to the surgical bed, plays an important role in the adjuvant scenario by improving local control ${ }^{(1-8)}$. The overall survival benefit of adjuvant RT for breast cancer patients was established in studies conducted more than 15 years ago $^{(8,9)}$. In those studies, however, radiation was delivered to the surgical bed and to all corresponding lymphatic drainage regions, including the axilla, supraclavicular fossa, and internal mammary lymph nodes (IMLNs). In patients with early stage tumors, conservative treatment is indicated, with no recommendation for irradiation of the lymph nodes, and therefore little is known about the effect that regional RT has on local control and overall survival. However, some studies have identified situations in which the lymph nodes, including the IMLNs, should be irradiated following conservative surgery ${ }^{(10-13)}$

In general, IMLN involvement is related to the axillary lymph node status and the location of the tumor in the breast. The IMLNs are involved in $18-52 \%$ of patients with positive axillary lymph nodes, regardless of the primary tumor location, compared with $0-16 \%$ for those with no axillary disease; among patients with tumors located in the inner quadrants, IMLN involvement occurs in $25-65 \%$ and $0-20 \%$ of those with positive and negative axillary lymph nodes, respectively ${ }^{(14-16)}$. Nevertheless, the rate of clinically detected recurrences in the IMLNs after primary breast treatment, mainly in the early stages, is $<10 \%^{(17-19)}$. Some authors suggest that this can be explained by incidental irradiation of the IMLN through opposed tangential fields $\mathrm{s}^{(13,20)}$.

An abstract presented at the American Society of Clinical Oncology annual meeting in $2011^{(21)}$ demonstrated increased disease-free survival in response to conservative surgery and locoregional RT including all the lymphatic chains in patients with breast cancer. Despite that improvement, the wide lymphatic irradiation did not allow treatment tailoring, leading the authors to improve their selection of the target volume regarding the lymph nodes: the supraclavicular fossa only; the IMLNs only; or both. In the few randomized studies published on this subject, no difference was observed between the studied groups in terms of local control or overall survival ${ }^{(11,22,23)}$. However, higher pulmonary toxicity is expected when the IMLNs are included in the irradiation fields. Therefore, IMLN irradiation is still controversial.

The RT target volumes are well defined for conventional two-dimensional (2D) and conformal three-dimensional (3D) RT techniques ${ }^{(24,25)}$. When the $3 \mathrm{D}$ technique is used, there can be incidental irradiation of certain areas, including the IMLNs. Incidental irradiation of the axillary lymph nodes through opposed tangential fields reportedly occurs in up to $22.3 \%$ of cases $^{(26)}$, although there have been no reports of such irradiation of the IMLNs.
As previously mentioned, the inclusion of the lymphatic drainage regions in the RT of breast cancer has the potential to improve survival. Therefore, the purpose of this study was to evaluate the incidental irradiation of the IMLNs in patients submitted to conventional 2D or conformal 3D RT, with no formal recommendation for irradiation of the IMLNs, as well as to compare the two treatment techniques in terms of the results obtained.

\section{MATERIALS AND METHODS}

This was a retrospective study of 80 breast cancer patients who underwent breast surgery and $2 \mathrm{D}$ or $3 \mathrm{D}$ RT between January and March 2012. Of those 80 patients, 40 were treated at a public facility and 40 were treated at a private facility. Consecutive patients were selected, and we included cases with no formal recommendation for irradiation of the IMLNs. The site of treatment, tumor stage, and type of surgery (mastectomy, breast-conserving surgery, or mastectomy with immediate reconstruction) were recorded for posterior comparisons.

For the patients treated at the public facility, the 2D technique with computed tomography for RT planning was employed, whereas the 3D RT technique was employed for those treated at the private facility. The total prescribed dose was $50.0 \mathrm{~Gy}$ or $50.4 \mathrm{~Gy}$, in conventional fractions of 2.0 or 1.8 Gy/day, respectively. In the 2D simulation, patients were immobilized with a breast board and the field borders (the medial border, at the midline; the lateral border, at the midaxillary line; the upper border, at the second intercostal space or including the whole breast with a 1-cm margin; and the lower border, $1-2 \mathrm{~cm}$ below the inferior breast fold) were marked on the skin. The beam angles were defined according to those marks, and the lung volumes were included in the tangential fields $-<3 \mathrm{~cm}$ (preferentially $<2 \mathrm{~cm}$ ) in the isocenter plane. The planning system was then optimized in order to achieve better dose distribution. In the 3D simulation, patients were immobilized with a vacuum cushion and the planning of the tangential fields was based on the target volume delineation for the dose-volume distribution analysis. In both techniques, the goal was better dose homogeneity-dose in the target volume ranging from $-5 \%$ to $+7 \%$, in accordance with the ICRU 50 recommendations ${ }^{(27)}$. Wedges and field-in-field strategies were used.

We reviewed all plans and defined the IMLNs following the Radiation Therapy Oncology Group (RTOG) recommendations ${ }^{(25)}$ : inclusion of the IMLNs from the superior aspect of the medial first rib to the cranial aspect of the fourth rib (Figure 1), ipsilateral to the treatment site, with a radial margin of $0.5 \mathrm{~cm}$ (Figure 2). After delineation, the IMLN volumes irradiated through the tangential fields were evaluated for both techniques (2D and 3D), as follows: proportion of the volume receiving at least $45 \mathrm{~Gy}(\mathrm{~V} 45$, the minimal dose required for subclinical disease control); dose to $95 \%$ of the volume (D95); minimum dose (Dmin); maximum dose (Dmax); mean dose (Dmean); the volume receiving at least 


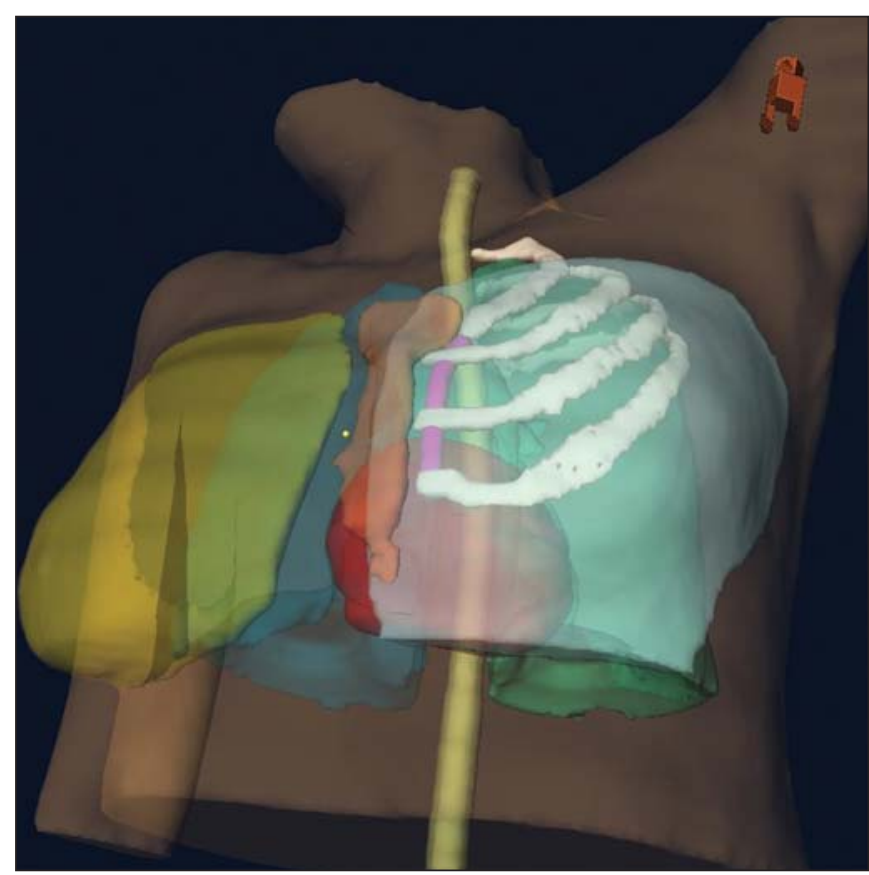

Figure 1. Internal mammary lymph node volume (pink): first, second, and third intercostal spaces.

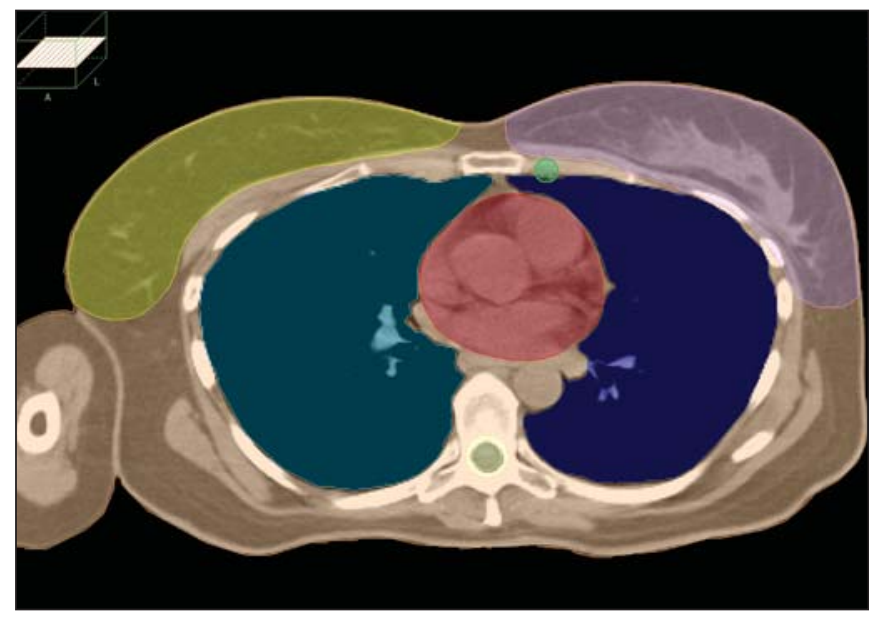

Figure 2. Volumes (lungs, heart, spinal cord, contralateral breast, clinical target, and internal mammary lymph nodes) contoured in accordance with RTOG Breast Cancer Atlas for Radiation Therapy Planning: Consensus Definitions.

$25 \mathrm{~Gy}$ (V25), corresponding to the field borders; and the dose to $50 \%$ of the IMLN volume (D50). The IMLN delineation results were also compared between both techniques.

Few patients received irradiation of the supraclavicular fossa or a boost to the surgical bed. However, those fields were not considered in the final calculation and dosimetric evaluation.

\section{RESULTS}

Left-sided treatments predominated in the 3D cohort. There were no statistically significant differences between the $2 \mathrm{D}$ and $3 \mathrm{D}$ techniques regarding tumor stage, type of surgery (Table 1), or mean IMLN contouring volume (6.8 $\mathrm{mL}$ vs. $5.9 \mathrm{~mL} ; p=0.411)$. Except for the Dmin, all of the
Table 1-Characteristics of the two cohorts studied.

\begin{tabular}{lccc}
\hline Characteristic & $2 \mathrm{D}$ & $3 \mathrm{D}$ & $P$ \\
\hline Treatment side & & & \\
$\quad$ Right & $22(55.0 \%)$ & $13(32.5 \%)$ & 0.033 \\
$\quad$ Left & $18(45.0 \%)$ & $27(67.5 \%)$ & \\
Tumor stage & $4(10.0 \%)$ & $8(20.0 \%)$ & \\
O & $6(15.0 \%)$ & $26(65.0 \%)$ & \\
IA & $11(27.5 \%)$ & $2(5.0 \%)$ & \\
IIA & $9(22.5 \%)$ & 0 & 0.093 \\
IIB & $7(17.5 \%)$ & 0 & \\
IIIA & $1(2.5 \%)$ & $2(5.0 \%)$ & \\
IIIB & $2(5.0 \%)$ & 0 & \\
IIIC & & & \\
Type of surgery & $23(57.5 \%)$ & $35(87.5 \%)$ & \\
Breast-consening & $11(27.5 \%)$ & 0 & 0.187 \\
Mastectomy & $6(15.0 \%)$ & $5(12.5 \%)$ & \\
Breast reconstruction & & & \\
\hline
\end{tabular}

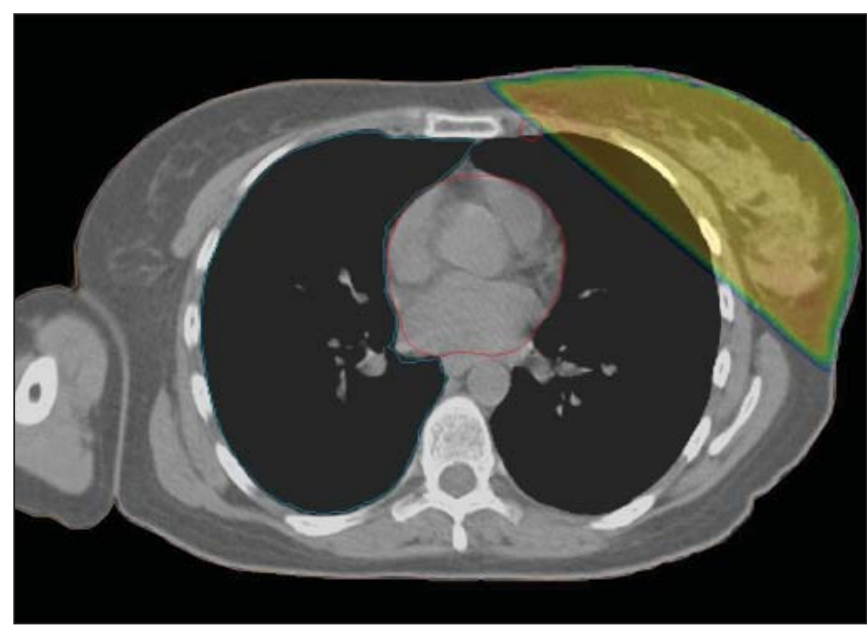

Figure 3. Internal mammary lymph nodes (red) and isodose curve (45 Gy; green).

dosimetric parameters analyzed (V45, D95, Dmax, Dmean, $\mathrm{V} 25$, and $\mathrm{D} 50)$ presented higher mean values in the 3D planning $(p<0.05)$. In the 3D planning, the median Dmax was $50.34 \mathrm{~Gy}$, although the IMLNs received a mean of 20.64 Gy, the V45 for the IMLNs being only $15.8 \%$ (Figure 3). Contouring and dosimetric results are depicted in Table 2.

\section{DISCUSSION}

Management of the IMLNs in breast cancer is still controversial. Clinical trials analyzing the surgical resection of IMLNs have shown no significant benefit in overall survival $^{(18,28-30)}$. In studies showing that postmastectomy RT provides a benefit, all lymph node chains, including the IMLNs, were irradiated, although no benefit was found to be specifically associated with IMLN irradiation ${ }^{(8,9,12)}$. In a phase II study involving 100 women at high-risk (with stage II-III breast cancer) submitted to doxorubicin-based chemotherapy and locoregional $\mathrm{RT}^{(31)}$, there were $33 \mathrm{who}$, for technical reasons, did not receive IMLN irradiation. Comparing 
Table 2-Comparison of the delineated volumes of the internal mammary lymph nodes and the dosimetric parameters between the 2D RT technique (performed at a public facility) and the 3D RT technique (performed at a private facility).

\begin{tabular}{|c|c|c|c|c|c|}
\hline Parameter & \multicolumn{2}{|c|}{$2 \mathrm{D}$} & \multicolumn{2}{|c|}{$3 D$} & $P$ \\
\hline IMLN volume $(\mathrm{mL})$ & $6.8(5-8.1)$ & $6.8(0.82)$ & $5.7(4.4-8.0)$ & $5.9(0.97)$ & 0.411 \\
\hline V45 (\%) & $0(0-27)$ & $2.2(5.6)$ & $7.5(0-96)$ & $15.8(23.5)$ & 0.020 \\
\hline D95 (cGy) & $196.6(44-742)$ & 228.1 (136.6) & $533.5(242-4609)$ & 753 (766) & $<0.0001$ \\
\hline Dmin (cGy) & $181.4(37-369)$ & $1790(80.2)$ & 470 (220-4414) & 639.5 (708) & $<0.0001$ \\
\hline Dmean (cGy) & $508.25(70-3245)$ & 793.5 (772.6) & $1811.5(438-5295)$ & 2064.2 (1331) & $<0.0001$ \\
\hline V25 (\%) & $0.35(0-53.7)$ & 7.8 (13.8) & $27.6(0-99.6)$ & 31.9 (29.8) & $<0.0001$ \\
\hline D50 (cGy) & $350.8(73-3430)$ & 619.7 (738.9) & $1193(50-5332)$ & $1746.7(1459.5)$ & $<0.0001$ \\
\hline
\end{tabular}

IMLN, Internal mammary lymph nodes; V45, proportion of the volume receiving at least 45 Gy; D95, dose to 95\% of the volume; Dmin, minimum dose; Dmax, maximum dose; Dmean, mean dose; V25, proportion of the volume receiving at least 25Gy; D50, dose to 50\% of the volume; SD, standard deviation.

the patients who did and did not receive IMLN irradiation, the authors found that, over the 77 months of follow-up, the disease-free survival rate was higher in the former group $(73 \%$ vs. $52 \% ; p<0.05)$, as was the overall survival benefit (78\% vs. $64 \% ; p=0.008)$. A study conducted in France analyzed the role of postmastectomy IMLN irradiation in 1407 women with breast cancer in an initial stage (I-II) and showed that most (86\%) of those women received systemic treatment ${ }^{(32)}$. The authors found no statistically significant difference between the women who received IMLN irradiation and those who did not in terms of the 10-year overall survival rate $(59.3 \%$ vs. $62.6 \%)$. Cardiac toxicity was reported in 7 of the patients who received IMLN irradiation and in 5 of those who did not ${ }^{(32)}$. In a cohort of 2413 women with T3-4 N0 breast cancer or positive lymph nodes, evaluated between 2001 and 2006 in British Columbia, Canada ${ }^{(33)}$, IMLN irradiation was not found to improve locoregional control or overall survival. However, when the authors of that study evaluated only the women with positive lymph nodes, they found that overall survival was better in those who received with IMLN RT than in those who did not $(91 \%$ vs. $88 \% ; p=0.01$ ).

The role of RT in local control and survival remains controversial and has been studied by many authors. In general, there is no difference between groups receiving and not receiving IMLN irradiation concerning local control and overall survival. However, pulmonary toxicity seems to be more common in the former. The negative survival benefit data observed for IMLN RT might be due to a low risk profile in the selected population or to a tendency in the study design to detect significant $(>10 \%)$ differences in survival ${ }^{(26)}$. Therefore, the hypothesis that there are minor benefits in overall survival or local control, mainly in women at high risk for IMLN involvement (i.e., those with inner quadrant tumors and axillary disease), cannot be excluded. The results from the largest phase III trial of irradiation of the supraclavicular fossa and the IMLNs ${ }^{(34)}$, which featured a 10-year follow-up period, were presented at the European Cancer Congress 2013. The authors demonstrated a tendency of such irradiation (in comparison with whole-breast or thoracic-wall irradiation alone) to increase overall survival $(82.3 \%$ vs. $80.7 \% ; p=0.056$ ), as well as a significant benefit in disease-free survival $(72.1 \%$ vs. $69.1 \% ; p=0.044)$ and in metastasis-free survival ( $78 \%$ vs. $75 \%$; $p=0.02)$, without treatment related morbidity, thus supporting the assumption that nodal irradiation provides benefits ${ }^{(11,31,35)}$.

The incidence of metastasis in the IMLNs varies according to the size and location of the tumor within the breast, as well as the axillary lymph node status. Therefore, for tumors with a diameter of $<0.5 \mathrm{~cm}$, the incidence of such metastasis is $3-7 \%$, whereas it is $40-60 \%$ for tumors ranging from $3.1 \mathrm{~cm}$ to $5 \mathrm{~cm}$ in diameter ${ }^{(36)}$. In patients with inner quadrant tumors and axillary lymph node involvement, the reported rate of IMLN involvement is $45 \%$ when the tumor is in the upper inner quadrant and $72 \%$ when it is in the lower inner quadrant ${ }^{(36)}$. Despite these high rates of IMLN involvement, the reported recurrence rates in the IMLN after the treatment of primary breast cancer are $<1 \%(19,37,38)$. One may argue that this could be due to the incidental irradiation of the IMLNs through the classic opposed tangential fields, which could deliver enough doses to achieve subclinical disease control.

Using clinical reference points, Proulx et al. ${ }^{(20)}$ planned and executed treatment with standard tangential fields in 50 women who had recently undergone either lumpectomy or mastectomy. Post-planning computed tomography scans were obtained, and the tangential radiation fields were visualized through the use of radiopaque markers affixed to the skin. The results were analyzed statistically for the frequency of inclusion of the IMLNs in the tangential radiation treatment portals as determined on the computed tomography scans. Among the 50 patients, the IMLNs were found to be completely within the tangential fields in only $14 \%$, partially within the tangential fields in $40 \%$, and completely outside the tangential fields in the remaining $46 \%$. However, those authors analyzed only the internal mammary vessels, did not define the clinical or planning target volume, and did not determine the dosimetry ${ }^{(20)}$. In a similarly designed study, 
Hare et al. ${ }^{(12)}$ showed complete or partial coverage of the IMLNs in $70 \%$ of the cases, without dosimetry. The authors suggested that this incidental irradiation partially explains the low failure rates in the IMLNs. Without a dose/volume measurement, it is difficult to ascertain the true clinical impact of incidental irradiation.

In the present study, we analyzed the true incidental dose in an RTOG-based IMLN volume in patients for whom IMLN irradiation was not specifically indicated. We quantified that irradiation with $2 \mathrm{D}$ and $3 \mathrm{D}$ techniques. The results were analyzed individually and compared between the two techniques. The mean D95 for the IMLN volume was $228.1 \mathrm{cGy}$ and $753.0 \mathrm{cGy}$ for the 2D and 3D techniques, respectively. The mean $\mathrm{V} 45$ for the IMLN volume was $2.2 \%$ and $15.8 \%$ for the $2 \mathrm{D}$ and $3 \mathrm{D}$ techniques, respectively. Therefore, the IMLN volumes did not receive a significant dose of incidental irradiation.

All dosimetric parameters are expected to be higher when the $3 \mathrm{D}$ technique is used than when the $2 \mathrm{D}$ technique is used. Although one may argue that this is related to the contouring, we found no difference between the two facilities under study in terms of contouring. In addition, most of the patients submitted to the $3 \mathrm{D}$ technique had early-stage breast cancer and had undergone breast-conserving surgery, unlike those submitted to the 2D technique (Table $1 ; p>0.05$ ). Patients treated at the public facility (i.e., those submitted to the 2D technique) presented disease that was more advanced. Consequently, mastectomy, which necessitates the inclusion of the chest wall in the radiation field, was performed in a larger number of cases at that facility. Even the fact that left-sided treatments could be more "economical", sparing the heart and reducing the IMLN coverage, might not explain our findings, because most left-sided treatments were performed in the $3 \mathrm{D}$ cohort. This supports the hypothesis that the higher doses observed with the $3 \mathrm{D}$ technique are a consequence of better planning of the target volume coverage due to better visualization of the target and of the organs at risk, as well as of the fact that the use of the 3D technique makes it possible to analyze the dose-volume histograms. In addition, neither the $3 \mathrm{D}$ nor the $2 \mathrm{D}$ technique allowed the minimal dose for subclinical disease control in the IMLNs to be attained.

\section{CONCLUSION}

Incidental irradiation of the IMLNs through opposed tangential fields does not provide adequate doses for subclinical disease control with the $2 \mathrm{D}$ or $3 \mathrm{D}$ RT techniques.

\section{REFERENCES}

1. Fisher B, Anderson S, Bryant J, et al. Twenty-year follow-up of a randomized trial comparing total mastectomy, lumpectomy, and lumpectomy plus irradiation for the treatment of invasive breast cancer. N Engl J Med. 2002;347:1233-41.

2. van Dongen JA, Voogd AC, Fentiman IS, et al. Long-term results of a randomized trial comparing breast-conserving therapy with mastectomy: European Organization for Research and Treatment of Cancer 10801 trial. J Natl Cancer Inst. 2000;92:1143-50.
3. Veronesi U, Cascinelli N, Mariani L, et al. Twenty-year follow-up of a randomized study comparing breast-conserving surgery with radical mastectomy for early breast cancer. N Engl J Med. 2002; 347:1227-32.

4. Veronesi U, Marubini E, Mariani L, et al. Radiotherapy after breastconserving surgery in small breast carcinoma: long-term results of a randomized trial. Ann Oncol. 2001;12:997-1003.

5. Liljegren G, Holmberg L, Bergh J, et al. 10-Year results after sector resection with or without postoperative radiotherapy for stage I breast cancer: a randomized trial. J Clin Oncol. 1999;17:2326-33.

6. Forrest AP, Stewart HJ, Everington D, et al. Randomized controlled trial of conservation therapy for breast cancer: 6-year analysis of the Scottish trial. Scottish Cancer Trials Breast Group. Lancet. 1996; 348:708-13.

7. Holli K, Hietanen P, Saaristo R, et al. Radiotherapy after segmental resection of breast cancer with favorable prognostic features: 12 year follow-up results of a randomized trial. J Clin Oncol. 2009; 27:927-32.

8. Overgaard M, Jensen MB, Overgaard J, et al. Postoperative radiotherapy in high-risk postmenopausal breast-cancer patients given adjuvant tamoxifen: Danish Breast Cancer Cooperative Group DBCG 82c randomised trial. Lancet. 1999;353:1641-8.

9. Overgaard M, Hansen PS, Overgaard J, et al. Postoperative radiotherapy in high-risk premenopausal women with breast cancer who receive adjuvant chemotherapy. Danish Breast Cancer Cooperative Group 82b Trial. N Engl J Med. 1997;337:949-55.

10. Matzinger $\mathrm{O}$, Heimsoth I, Poortmans $\mathrm{P}$, et al. Toxicity at three years with and without irradiation of the internal mammary and medial supraclavicular lymph node chain in stage I to III breast cancer (EORTC trial 22922/10925). Acta Oncol. 2010;49:24-34.

11. Chetty U, Jack W, Prescott RJ, et al. Management of the axilla in operable breast cancer treated by breast conservation: a randomized clinical trial. Edinburgh Breast Unit. Br J Surg. 2000;87:163-9.

12. Hare GB, Proulx GM, Lamonica DM, et al. Internal mammary lymph node (IMN) coverage by standard radiation tangent fields in patients showing IMN drainage on lymphoscintigraphy: therapeutic implications. Am J Clin Oncol. 2004;27:274-8.

13. Ragaz J, Olivotto IA, Spinelli JJ, et al. Locoregional radiation therapy in patients with high-risk breast cancer receiving adjuvant chemotherapy: 20-year results of the British Columbia randomized trial. J Natl Cancer Inst. 2005;97:1 16-26.

14. Morimoto T, Monden Y, Takashima S, et al. Five-year results of a randomized clinical trial comparing modified radical mastectomy and extended radical mastectomy for stage II breast cancer. Surg Today. 1994;24:210-4.

15. Chen RC, Lin NU, Golshan M, et al. Internal mammary nodes in breast cancer: diagnosis and implications for patient management a systematic review. J Clin Oncol. 2008;26:4981-9.

16. Strom EA, McNeese MD. Postmastectomy irradiation: rationale for treatment field selection. Semin Radiat Oncol. 1999;9:247-53.

17. Veronesi U, Valagussa P. Inefficacy of internal mammary nodes dissection in breast cancer surgery. Cancer. 1981;47:170-5.

18. Buzdar AU, McNeese MD, Hortobagyi GN, et al. Is chemotherapy effective in reducing the local failure rate in patients with operable breast cancer? Cancer. 1990;65:394-9.

19. Zhang YJ, Oh JL, Whitman GJ, et al. Clinically apparent internal mammary nodal metastasis in patients with advanced breast cancer: incidence and local control. Int J Radiat Oncol Biol Phys. 2010;77: $1113-9$.

20. Proulx GM, Lee RJ, Stomper PC. Internal mammary lymph node inclusion in standard tangent breast fields: effects of body habitus. Breast J. 2001;7:111-6.

21. Whelan TJ, Olivotto I, Ackerman I, et al. NCIC-CTG MA.20: An intergroup trial of regional nodal irradiation in early breast cancer. J Clin Oncol. 2011;29(suppl; abstr LBA1003). 
22. Kaija H, Maunu P. Tangential breast irradiation with or without internal mammary chain irradiation: results of a randomized trial. Radiother Oncol. 1995;36:172-6.

23. Hennequin C, Bossard N, Servagi-Vernat S, et al. Ten-year survival results of a randomized trial of irradiation of internal mammary nodes after mastectomy. Int J Radiat Oncol Biol Phys. 2013;86:860-6.

24. Recht A. Breast cancer: stages I and II. In: Gunderson LL, Tepper JE, editors. Clinical radiation oncology. 3rd ed. Philadelphia, PA: Elsevier Saunders; 2012. p. 1321-38.

25. RTOG - Radiation Therapy Oncology Group. Breast cancer atlas for radiation therapy planning: consensus definitions. [cited 2014 Oct 25]. Available from: http://www.rtog.org/LinkClick.aspx? fileticket $=$ vzJFhPaBipE\%3d\&tabid $=236$.

26. Bonavitacola P, Sioshansi S, Rava PS, et al. Incidental axillary coverage comparasion between 3DCRT and hybrid IMRT for whole breast irradiation. Int J Radiat Oncol Biol Phys. 2012;84(3 Suppl): S228.

27. Lee JW, Hong S, Choi KS, et al. Performance evaluation of fieldin-field technique for tangential breast irradiation. Jpn J Clin Oncol. 2008;38:158-63.

28. Meier P, Ferguson DJ, Karrison T. A controlled trial of extended radical versus radical mastectomy. Ten-year results. Cancer. 1989; 63:188-95.

29. Lacour J, Lê M, Caceres E, et al. Radical mastectomy versus radical mastectomy plus internal mammary dissection. Ten year results of an international cooperative trial in breast cancer. Cancer. 1983; 51:1941-3.

30. Lacour J, Lê MG, Hill C, et al. Is it useful to remove internal mammary nodes in operable breast cancer? Eur J Surg Oncol. 1987;13: 309-14.
31. Stemmer SM, Rizel S, Hardan I, et al. The role of irradiation of the internal mammary lymph nodes in high-risk stage II to IIIA breast cancer patients after high-dose chemotherapy: a prospective sequential nonrandomized study. J Clin Oncol. 2003;21:2713-8.

32. Romestaing P, Belot A, Hennequin C, et al. Ten-year results of a randomized trial of internal mammary chain irradiation after mastectomy. Int J Radiat Oncol Biol. Phys. 2009;75(Suppl):S1.

33. Olson RA, Woods R, Speers C, et al. Does the intent to irradiate the internal mammary nodes impact survival in women with breast cancer? A population-based analysis in British Columbia. Int J Radiat Oncol Biol Phys. 2012;83:e35-41.

34. Poortmans, Collette S, Kirkove C, et al. Internal mammary and medial supraclavicular irradiation in breast cancer. N Engl J Med. 2015;373:317-27.

35. Poortmans PM, Venselaar JL, Struikmans H, et al. The potential impact of treatment variations on the results of radiotherapy of the internal mammary lymph node chain: a quality-assurance report on the dummy run of EORTC Phase III randomized trial 22922/10925 in Stage I-III breast cancer(1). Int J Radiat Oncol Biol Phys. 2001; 49:1399-408.

36. Handley RS. Carcinoma of the breast. Ann R Coll Surg Engl. 1975;57:59-66.

37. Galper S, Recht A, Silver B, et al. Factors associated with regional nodal failure in patients with early stage breast cancer with 0-3 positive axillary nodes following tangential irradiation alone. Int J Radiat Oncol Biol Phys. 1999;45:1157-66.

38. Stefanik D, Goldberg R, Byrne P, et al. Local-regional failure in patients treated with adjuvant chemotherapy for breast cancer. J Clin Oncol. 1985;3:660-5. 